\title{
Megaloblastic anaemia due to sulphasalazine responding to drug withdrawal alone
}

\author{
A. Grieco, S. Caputo, A. Bertoli, P. Caradonna and A.V. Greco \\ Istituto di Clinica Medica, Universita' Cattolica del Sacro Cuore, Largo A. Gemelli 8, 00168 Roma, Italy.
}

\begin{abstract}
Summary: A 60 year old man with ulcerative colitis since 1975 and treated with sulphasalazine, presented with severe megaloblastic anaemia caused by folate deficiency. The drug was stopped, and the anaemia recovered promptly. There was no relapse one year later.
\end{abstract}

\section{Introduction}

Folate deficiency is a frequent complication in patients with inflammatory bowel disease (Franklin \& Rosenberg, 1973). Salicylazosulphapyridine (sulphasalazine), a drug commonly used for treating ulcerative colitis, can interfere with the absorption of folates (Halsted et al., 1981). Nevertheless, megaloblastic anaemia caused by folate deficiency is rare in patients with ulcerative colitis treated with this drug.

We describe a patient with ulcerative colitis treated with sulphasalazine for 9 years who developed a megaloblastic anaemia caused by folate deficiency that recovered following withdrawal of the drug only.

\section{Case report}

A 60 year old farmer was admitted to our department in March 1984. He had suffered from ulcerative colitis since 1975 and was regularly treated with sulphasalazine $(2 \mathrm{~g} /$ day $)$. He had had severe weakness and vague abdominal pain for the last 2 months, but no fever or gastrointestinal bleeding. His diet was adequate.

Clinical examination showed poor general condition and profound pallor. There was no liver, spleen or lymph gland enlargement and no other sign of nutritional deficiency. Haematocrit was 0.17 , haemoglobin concentration $5.3 \mathrm{~g} / \mathrm{dl}$, reticulocyte count $0.6 \%$, mean corpuscular volume $115 \mathrm{fl}$, leucocyte count $3.2 \times 10^{9} / 1$, platelet count $95 \times 10^{9} / 1$, iron $32.9 \mu \mathrm{mol} / 1$ and indirect Coomb's test negative. A marrow aspirate showed a decreased myeloid/erythroid ratio with megaloblastic erythropoiesis. Serum folate was $1.82 \mathrm{nmol} / 1$ (normal range 5.45-39.72 $\mathrm{nmol} / \mathrm{l}$ ); serum vitamin B12 was $355 \mathrm{pmol} / 1$ (normal range $185-739 \mathrm{pmol} / \mathrm{l})$.

Correspondence: A. Grieco, M.D.

Accepted: 6 August 1985
A radiological and endoscopic evaluation of the upper gastrointestinal tract showed no evidence of acute or chronic disease. Basal gastric acid secretion was normal. The D-xylose absorption-excretion test was normal. No pathological condition of the small intestine was found by barium meal. Radiology, endoscopy and histological examinations showed ulcerative colitis extending up to the transverse colon. The pattern was not different from the one shown in 1983, when routine haematological tests failed to show any abnormality. Subsequently he was given no other drugs. On withdrawal of sulphasalazine a rapid and progressive haematological improvement was observed. He was discharged from the hospital in May 1984 when his most recent haemoglobin was $12.1 \mathrm{~g} / \mathrm{dl}$, reticulocytes $0.8 \%$, serum folate $26.15 \mathrm{nmol} / 1$, serum vitamin B12 $355 \mathrm{pmol} / \mathrm{l}$. One year later he is still well and without clinical signs of active disease.

\section{Discussion}

Several toxic effects of sulphasalazine therapy on the blood have been described, including agranulocytosis, leucopenia, pancytopenia, thrombocytopenia, anaemia, haemolytic anaemia with or without Heinz bodies and sulphhaemoglobinaemia (Collins, 1968; Pounder et al., 1975; Taffet \& Das, 1983; Das, 1983).

Recently, megaloblastic anaemia during sulphasalazine therapy has been reported (Schneider \& Beeley, 1977; Kane \& Boots, 1977), but this seems to be rare. In the report by Swinson et al. (1981) only $10 \%(8 / 80)$ of the patients with ulcerative colitis treated with sulphasalazine had folate deficiency and only $5 \%(4 / 80)$ had megaloblastic anaemia. Moreover, these patients had other causes for the folate deficiency (Swinson et al., 1981). In the series reported by Pounder et al. (1975) frequency of folate deficiency in patients with ulcerative colitis was also very low. It has 
been suggested that sulphasalazine may play an antifolate role by interfering with folate metabolism in the liver (Selhub et al., 1978) and by producing folate malabsorption (Franklin \& Rosenberg, 1973; Halsted et al., 1981). Our patient had a normal value of vitamin B12, a low folate level, and the low reticulocyte count excluded other causes of anaemia. Small bowel study and the D-xylose test showed no signs of malabsorption. On the other hand, sulphasalazine was certainly the cause of folate deficiency since on withdrawal of the drug the haematological pattern recovered. It is very interesting that in this case the toxic effects arose after about 9 years of continuous use of the drug and

\section{References}

COLLINS, J.R. (1968). Adverse reactions to salicylazosulfapyridine (Azulfidine) in the treatment of ulcerative colitis. Southern Medical Journal, 64, 517.

DAS, K.M. (1983). Pharmacotherapy of inflammatory bowel disease. Part 1. Sulfasalazine. Postgraduate Medicine, 74, 141.

FRANKLIN, J.L. \& ROSENBERG, I.H. (1973). Impaired folic acid absorption in inflammatory bowl disease: effects of salicylazosulfapyridine (Azulfidine). Gastroenterology, 64, 517.

HALSTED, C.H., GANDHI, G. \& TAMURA, T. (1981). Sulfasalazine inhibits the absorption of folates in ulcerative colitis. New England Journal of Medicine, 305, 1513.

KANE, S.P. \& BOOTS, M.A. (1977). Megaloblastic anaemia associated with sulphasalazine treatment. British Medical Journal, 2, 1287. quite suddenly: only one year before, the patient's haematological values had been within normal limits. His life style and diet had not changed. Commonly the haematological side effects of sulphasalazine are considered non-dose-dependent and consequently they arise at the beginning of therapy (Taffet \& Das, 1983). Our patient suddenly developed severe anaemia after 9 years of therapy and no other cause of folate deficiency could be detected. It would be useful to assess folate body content periodically during chronic sulphasalazine therapy, perhaps by measuring red cell folate content.

POUNDER, R.E., CRAVEN, E.R., HENTHORN, J.S. \& BANNATYNE, J.M. (1975). Red cell abnormalities associated with sulphasalazine maintenance therapy for ulcerative colitis. Gut, 16, 181.

SCHNEIDER, R.E. \& BEELEY, L. (1977). Megaloblastic anaemia associated with sulphasalazine treatment. British Medical Journal, 1, 1638.

SELHUB, J., DHAR, G.J. \& ROSENBERG, I.H. (1978). Inhibition of folate enzymes of sulphasalazine. Journal of Clinical Investigation, 61, 221.

SWINSON, C.M., PERRY, J., LUMB, M. \& LEVI, A.J. (1981). Role of sulphasalazine in the aetiology of folate deficienc in ulcerative colitis. Gut, 22, 456.

TAFFET, S.L. \& DAS, K.M. (1983). Sulfasalazine. Adverse effect and desensitization. Digestive Diseases and Science 28, 833 . 